\title{
Anxiety and encoding strategy
}

\author{
JUDY C. SCOTT and DOUGLAS L. NELSON \\ University of South Florida, Tampa, Florida 33620
}

\begin{abstract}
High- and low-anxious subjects learned paired-associate lists under interaction imagery or under repetition instructions. When contrasted with the results of an earlier and similar experiment, the findings suggest that performance deficits associated with high anxiety can be reduced by effective encoding strategies. This reduction, however, is apparent only when time-pressure constraints are not present during testing.
\end{abstract}

Little is known about how anxiety interacts with other variables that affect memory performance. Several investigators have suggested that high arousal is associated with a reduction in the encoding of meaning and an increased tendency to concentrate on the physical features of the stimuli (e.g., Mueller, 1976, 1977, 1978). Others have suggested that high arousal may be associated with deficits in encoding strategy (Edmundson \& Nelson, 1976). For example, the latter authors had high- and low-anxious subjects learn a paired-associate list containing stimulus words that were high or low in physical similarity. In addition, subjects were given either an effective encoding strategy that encouraged interaction imagery or an ineffective one that required them to continuously repeat the pairs aloud. The results indicated that subjects who displayed high state anxiety during the experiment were more impaired by high similarity. Furthermore, when the low-similarity data were analyzed separately, high- and low-trait anxious subjects performed equally well, but only when the instructions had conveyed the imagery strategy. When they required mere repetition, high-anxious subjects performed more poorly. Thus, when high-trait anxious subjects were given a more effective encoding strategy, their performance was more similar to that of lowtrait anxious subjects.

The present study was designed to replicate this apparent interaction between anxiety and instructions. The same procedures as those used by Edmundson and Nelson (1976) were employed, with two exceptions. First, test trials were paced at $3 \mathrm{sec}$ instead of being self-paced. Second, subjects were selected as having both high-trait and high-test anxiety or both low-trait and low-test anxiety. The dual criterion was used to enhance the likelihood of obtaining effects related to the anxiety manipulation.

This research was supported by Grant MH16360 to the second author from the National Institute of Mental Health. This research served to partially fulfill the requirements for the MA degree for the first author. Requests for reprints should be sent to Douglas L. Nelson, Department of Psychology, University of South Florida, Tampa, Florida 33620.

\section{METHOD}

\section{Design and Subjects}

The design was a 2 by 2 factorial involving two betweensubjects variables, anxiety and instructions. There were 16 subjects in each condition. All were volunteers from introductory psychology classes at the University of South Florida. Extra-credit points were given for participation.

The classes were given the State-Trait Anxiety Inventory (STAI) and the Test Attitude Inventory (TAI) (Spielberger, Anton, Gonzalez, \& Taylor, 1976; Spielberger, Gorsuch, \& Lushene, 1969). Two groups of students with extreme scores were then selected for inclusion in the experiment. Those with STAI A-Trait scores in the upper $25 \%$ of the class and TAI scores above the median were designated as high anxious. Students with STAI A-Trait scores in the lower $25 \%$ and TAI scores below the median of the class were designated as low anxious. The use of TAI scores resulted in the exclusion of $21 \%$ of the subjects classified as either high or low anxious on the basis of their STAI scores. The number excluded was essentially identical for both extreme groups. The mean trait and test anxiety scores for each of the instruction groups were essentially equal.

\section{Materials}

Two lists of 20 stimulus-response pairs were used. All words were low in similarity, chosen to be as different from one another as possible with respect to phonetic similarity and obvious semantic associations. Both stimulus and response items had concreteness ratings of 5.0 or higher according to the Paivio, Yuille, and Madigan (1968) norms.

\section{Procedure}

Individual session practice was by the study-test method, with all subjects continuing the task until they reached a criterion of one errorless trial. During the study trials, each subject attempted to learn the word pairs according to the strategy given during the instructional period. During the test trials, each subject was required to pronounce the stimulus word presented and to attempt to say the correct response. Guessing was encouraged. All items within a study or test trial were presented by a slide projector and were arranged in random order. The only restriction was that at least four slides appeared between any stimulus-response pair and the corresponding stimulus test slide. Presentations were paced at $3 \mathrm{sec}$ during both study and test.

The instructions described the study-test procedure and a "most efficient" learning strategy for each instructional set. Subjects in the interacting imagery condition were told to construct an interactive mental picture or image involving the referents for both words in the pair. Subjects were told that it did not matter if the image was bizarre, and they were tested on 
an example. The experimenter provided feedback discouraging separation imagery and encouraging interaction imagery (Bower, 1970). Subjects given repetition instructions were told to learn what words went together by repeating the words aloud continuously until the next pair was shown. A practice task was given to insure understanding of the procedures. Each subject was shown six word pairs, followed by a single test trial.

Immediately after practice, they were presented with the experimental task. As soon as criterion was reached, the STAI A-State scale was administered. Subjects were given retrospective instructions indicating that they were to respond to the questionnaire according to how they felt during the experintent. Admittedly, state anxiety levels may have fluctuated from the initial trials to the later trials, but the use of a retrospective measure was based on a desire to preserve the experimental task intact.

\section{RESULTS AND DISCUSSION}

The left two columns of Table 1 present mean total errors per subject as a function of anxiety level and instructions. Comparison of these values indicated that the interacting imagery strategy improved performance relative to the repetition strategy. High anxiety was associated with poor performance relative to low anxiety, but only in the imagery condition. An analysis of variance indicated that instructional set $[\mathrm{F}(1,60)=$ 9.12] and the interaction of Anxiety by Instructional Set $[F(1,60)=6.68, \mathrm{MSe}=257.88]$ were significant at $\mathrm{p}<.05$. Fisher's two-tailed least significant difference (1.s.d.) for comparison among the interaction means was 11.24. Thus, the analysis of variance confirmed obvious effects. High anxiety was associated with poor performance, but only under imagery instructions. Of course, this finding is exactly the opposite of that reported by Edmundson and Nelson (1976).

To determine the reliability of these opposing trends, the data from the present experiment were combined with comparable data from Edmundson and Nelson. Their values are presented in the rightmost columns of Table 1. An analysis of variance of all data indicated that experiment $[F(1,120)=5.75]$, instructional set $[F(1,120=22.34]$, and the three-way interaction of Experiment by Instructional Set by Anxiety $[\mathrm{F}(1,120)=$ 10.46] were all reliable at $\mathrm{p}<.05$, with $\mathrm{MSe}=195.12$. Fisher's 1.s.d. for this interaction was 9.78. Thus, the reversal of effect was apparently reliable. In the present experiment, high anxiety was associated with poor performance under imagery instructions, but not under repetition instructions. In contrast, in the Edmundson and Nelson (1976) experiment, high anxiety was asso- ciated with poor performance under repetition instructions, but not under imagery instructions.

One possible explanation for the differences in the pattern of findings is that there were differences between the experiments in manipulated anxiety levels. However, mean trait anxiety scores were virtually identical in the two experiments. In the present study, mean trait anxiety scores were 53.04 and 26.65 , respectively, for high- and low-anxious subjects; in the Edmundson and Nelson experiment, these values were 51.07 and 29.66. Moreover, the retrospective measure of state anxiety also indicated that subjects were fairly comparable in the two studies. Mean high and low state anxiety scores were 46.35 and 34.03 in the present experiment; they were 48.78 and 38.88 in the Edmundson and Nelson study. Thus, even though subjects in the present experiment were also selected on the basis of test anxiety scores, they apparently were no more or less aroused by the performance of the task than subjects serving in the Edmundson-Nelson study. The differential error pattern cannot be attributed to differences in aroused anxiety.

Test rate is the procedural difference that seems most likely to be responsible for the discrepant pattern. Postexperimental descriptions of how each pair was learned suggested that high-anxious subjects had formed appropriate images as often as low-anxious subjects, and that there were essentially no differences between experiments. However, high-anxious subjects serving in the imagery condition frequently complained that the test rate was too fast. They presumably had trouble recalling their images in the time allowed. Thus, it appears that the high-anxious subjects in the EdmundsonNelson experiment had sufficient time to reinstate their study trial encoding and, as a consequence, their performance was similar to that of low-anxious subjects. When limited to $3 \mathrm{sec}$ for responding, high-anxious subjects were apparently unable to take full advantage of the more effective encoding. Conceivably, anxious subjects are more likely to divide their attention between internal and external cues; consequently, their performance is more likely to suffer when time or other constraints are imposed (e.g., Marlett \& Watson, 1968; Sarason, 1960; Wine, 1971). Thus, if the present interpretation is correct, the performance deficits normally associated with high anxiety can be eliminated if subjects are pretrained in using an effective encoding strategy. However, the benefits of the superior strategy

Table 1

Mean Errors and Standard Deviations as a Function of Anxiety, Instructional Set, and Experiment

\begin{tabular}{|c|c|c|c|c|c|c|c|c|}
\hline \multirow[b]{3}{*}{ Instructions } & \multicolumn{4}{|c|}{ Present Experiment } & \multicolumn{4}{|c|}{ Edmundson and Nelson } \\
\hline & \multicolumn{2}{|c|}{ High-Anxious } & \multicolumn{2}{|c|}{ Low-Anxious } & \multicolumn{2}{|c|}{ High-Anxious } & \multicolumn{2}{|c|}{ Low-Anxious } \\
\hline & Mean & SD & Mean & SD & Mean & SD & Mean & SD \\
\hline Repetition & 30.25 & 12.41 & 39.31 & 24.53 & 34.56 & 16.03 & 22.25 & 8.20 \\
\hline Imagery & 39.50 & 12.43 & 16.81 & 11.05 & 17.17 & 10.54 & 16.63 & 9.69 \\
\hline
\end{tabular}


will be obvious only if time constraints are reduced or eliminated during testing.

A comment on one other finding deserves mention. In the present experiment, several low-anxious subjects receiving the repetition instructions performed at a very low level. As a result, the variance in this condition is comparatively higher than in the other conditions and the mean is substantially elevated relative to that reported by Edmundson-Nelson. At the present time, we have no satisfactory explanation for this finding except to note that these subjects seemed to be remarkably uninvolved, almost untouched by the task and its requirements.

\section{REFERENCES}

BowER, G. H. Imagery as a relational organizer in associative learning. Journal of Verbal Learning and Verbal Behavior, 1970, 9, 529-533.

Edmundson, E. D., \& Nelson, D. L. Anxiety, imagery, and sensory interference. Bulletin of the Psychonomic Society, 1976, 8, 319-322.

Marlett, N. J., \& Watson, D. Test anxiety and immediate or delayed feedback in a test-like avoidance task. Journal of Personality and Social Psychology, 1968, 8, 200-203.
Mueller, J. H. Anxiety and cue utilization in human learning and memory. In M. Zuckerman \& C. D. Spielberger (Eds.), Emotions and anxiety: New concepts, methods, and applications. Hillsdale, N.J: LEA/Wiley, 1976.

Mueller, J. H. Test anxiety, input modality, and levels of organization in free recall. Bulletin of the Psychonomic Society, 1977, 9, 67-69.

Mueller, J. H. The effects of individual differences in test anxiety and type of orienting task on levels of organization in free recall. Journal of Research in Personality, 1978, 12, 100-116.

Paivio, A., Yuille, J. C., \& Madigan, S. Concreteness, imagery, and meaningfulness values for 925 nouns. Journal of Experimental Psychology Monograph Supplement, 1968, 76, Pt. 2.

SaRAson, I. G. Empirical findings and theoretical problems in the use of anxiety scales. Psychological Bulletin, 1960, 57, 403-415.

Spielberger, C. D., Anton, W. D., Gonzalez, H. P., \& TAYLOR, C. Test Anxiety inventory. New York: Academic Press, 1976.

Spielberger, C. D., Gorsuch, P., \& Lushene, R. StateTrait Anxiety Inventory: Preliminary test manual. Palo Alto, Calif: Consulting Psychologist Press, 1969.

Wine, J. Test anxiety and direction of attention. Psychological Bulletin, 1971, 76, 92-104.

(Received for publication January 31, 1979.) 